\title{
Measuring Security Awareness on Mobile Money Users in Tanzania
}

\author{
Augustine Malero \\ Assistant Lecturer, Department of Computer Science, University of Dodoma \\ P.O. 490, Dodoma, Tanzania
}

\begin{abstract}
Mobile Money has placed itself as a means for banking services for the unbanked in the developing world. Due to the ease of using the service, the number of subscribers using the service has increased tremendously. However, security concerns have also been raised as the service relies on customer identification document and PIN for authentication mechanisms. In this study a list of questions were posed to respondents with different levels of education, gender and age. The questions were intended to measure the level of security awareness when using M-Money services among the respondents. Results reveal that generally respondents have a high level of understanding. It is also noted that respondents with higher levels of education and those falling within the age group 25-36 years are more aware than respondents of other groups.
\end{abstract}

Keywords-M-Money, security, Awareness study

\section{INTRODUCTION}

Mobile Money (M-Money) is a term referring to the services that cover mobile money transactions over a mobile phone also known as mobile wallet or mobile transaction [1]. Mobile money allows customers to use their mobile phones to deposit and withdraw money, transfer money to other users and non-users, make balance inquiry, pay bills, purchase airtime and transfer money between the service and a bank. These services are operated under financial regulations and performed from or via a mobile device. M-Money customers can deposit and withdraw money from a network of agents that includes airtime re-sellers and retail outlets acting as banking agents.

M-Money in Tanzania started in 2008 when Vodacom introduced M-pesa after a successful experience in Kenya. Zantel, Airtel and Tigo later joined the business through ZPesa (now called Easypesa), Airtel Money and tigo pesa brands respectively. According to an industry report by the Global System for Mobile Association (GSMA), as of September 2013, 90\% of the population in Tanzania had access to mobile financial services, up from $1 \%$ in 2008 taking a lead in mobile money usage in Sub-Saharan Africa [2].The Monetary Policy Statement[3] reveals that The mobile phone financial service has also enhanced the use of financial services such as remittances to 33.1 percent of adults, savings to 25.6 percent of adults and payments of bills, fees and business transactions to 9.9 percent of adults. The recent launch of M-Pawa, Airtel timiza and tigo Wekeza that offer interest to M-Money savers, avail banking services to small savers and borrowers through the mobile phone, hugely increasing the potential of expanding the reach of banking services to the previously under-banked.

Following the success of the M-Money industry in Tanzania, perception and receptiveness of the services among
Tanzanians has been widely researched, among which security seems to be the main concern [4], [5], [6], and [7]. Mobile Money in Tanzania is threatened by privacy and security concerns, opening the door for abuse and erosion of the application's utility.

Although a number of initiatives have been put in place by Mobile Money Operators (MMOs) to insure security is safeguarded when using the services such as installation of firewalls and intrusion detection systems, M-Money still relies on Customer Identification Document (ID) and PIN for authentication mechanisms. When a customer registers for the service to an agent, his/her account is linked to a single ID and PIN that should be used whenever making transactions. Both the ID and PIN should be kept secure and used only by the owner [8]. Types of identification that are allowed include a voter's card, driver's license, valid passport and an introduction letter from the village or ward executive officer (which must bear a full name and photograph of the applicant). Other accepted customer IDs are employment ID, college or student ID, pension fund ID, tax ID and national ID [9]. M-Money systems confirm every transaction made by an SMS followed by provision of an updated balance of the account after the transaction. These systems rely on the use of the valid PIN as conclusive evidence that a debit transaction was authorized by a customer even if it were made without customer's authority and consent. Upon completion of the transaction, a unique receipt number is issued in the confirmation SMS that is sent to the customer. This number can be used for tracking and identifying all transactions carried by the customer and/or agent [8].

The use of the valid PIN as an evidence that the transaction was made by a legitimate customer, calls for a customer's attention towards keeping his/her details in a safe way to avoid any security breaches associated with exposing the same. According to Ally [5], a number of cases have been reported to Tanzanian police where money was stolen from M-Money. Mtaho et al [4] too call for a concern over the weak security mechanisms used by the service providers.

This study attempts to measure the security awareness in M-money usage to different groups of customers. As fraudulent and non-fraudulent issues increase day by day, user awareness on security awareness is very important to protect users from unauthorized access. The objective of this study is to investigate the demographic differences in M-money security awareness in Tanzania. This is very important to determine the level of awareness that the respondents have in terms of M-money usage.

The remainder of this paper proceeds as follows; the next section describes the methodology of survey, which details out the form of questionnaire and source of data. The 
following section reports the findings of the survey analysed with respect to the objective of this study. Next section discusses the findings and implications before the paper concludes with some direction for future research.

\section{METHODOLOGY}

A questionnaire for this study was created on-line using Google forms and later distributed using mailing lists and social networks to respondents. There were 134 male respondents and 41 female respondents making a total of 175 respondents. Academically, 31 respondents had a Certificate of Secondary Education (CSE) or below qualifications, 44 were pre-University and 100 had at least a bachelor's degree.

The questions in the survey were designed based on a document "General Information Security Best Practices" as used by Sidi et al [10]. The computer security awareness questionnaire consisted of 8 questions centred on determining the security awareness to M-Money users on the use of different services offered by the same. The list of questions used is on Table 1.

\section{FINDINGS AND DISCUSSIONS}

All survey responses received were recorded and later used for statistical analysis. Data were gathered using the Google forms and the descriptive cross tabulation method using Spreadsheets was used to conduct the data analysis.

The analysis describes the findings based on gender, age and the level of education of the respondents.

TABLE 1

SURVEY QUESTIONS

\begin{tabular}{|l|l|}
\hline No & Question \\
\hline 1 & $\begin{array}{l}\text { Do you change your PIN codes regularly (at least within 3 } \\
\text { months)? }\end{array}$ \\
\hline 2 & $\begin{array}{l}\text { Do you create unique password that is difficult to use? That is } \\
\text { not based on your year of birth, spouse birth date, 1234, etc? }\end{array}$ \\
\hline 3 & $\begin{array}{l}\text { Do you make sure no one is at your back to view your PIN } \\
\text { when making a transaction? }\end{array}$ \\
\hline 4 & $\begin{array}{l}\text { Do you always check your account balances/statements to } \\
\text { check for any unauthorized transaction? }\end{array}$ \\
\hline 5 & $\begin{array}{l}\text { Do you save your PIN in the Saved items of your mobile phone } \\
\text { for easy remembrance? }\end{array}$ \\
\hline 6 & $\begin{array}{l}\text { If asked by a spouse in case she/he has forgotten it, do you } \\
\text { share your PIN using an SMS? }\end{array}$ \\
\hline 7 & $\begin{array}{l}\text { Can you share your PIN to a close person other than your } \\
\text { spouse so that they may make a transaction for you? }\end{array}$ \\
\hline 8 & $\begin{array}{l}\text { When making a transaction, can you share your password with } \\
\text { an agent who is assisting you in case you need his help? }\end{array}$ \\
\hline
\end{tabular}

Below an analysis of the results from the survey is given covering the level of security awareness for each question posed and the summary of the average awareness for gender, level of education and age.

\section{A. M-Money Security Awareness Based on Gender}

Results show that the highest level of awareness for both males and females was observed on question number 5 where males had $82.82 \%$ and females had $82.37 \%$ level of awareness. That is most respondents do not save their passwords in their handsets. The worst level of security awareness were $19.4 \%$ for males and $17.07 \%$ for females observed on question number 1 . This means the respondents interviewed do not change their PIN codes regularly showing a low level of awareness on the risks associated with this practice. There is however no significance difference in awareness between men and women.

TABLE II

M-MONEY SECURITY AWARENESS BASED ON GENDER

\begin{tabular}{|l|l|l|l|l|}
\hline \multirow{2}{*}{ ID } & \multicolumn{2}{|c|}{ Male } & \multicolumn{2}{c|}{ Female } \\
\cline { 2 - 5 } & $\begin{array}{c}\text { Aware } \\
(\mathbf{\%})\end{array}$ & $\begin{array}{c}\text { Un aware } \\
(\mathbf{\%})\end{array}$ & $\begin{array}{c}\text { Aware } \\
(\mathbf{\%})\end{array}$ & $\begin{array}{c}\text { Un aware } \\
(\mathbf{\%})\end{array}$ \\
\hline 1 & 19.40 & 80.60 & 17.07 & 82.93 \\
\hline 2 & 67.41 & 32.59 & 60.00 & 40.00 \\
\hline 3 & 81.48 & 18.52 & 79.49 & 20.51 \\
\hline 4 & 56.72 & 43.28 & 60.98 & 39.02 \\
\hline 5 & 85.82 & 14.18 & 85.37 & 14.63 \\
\hline 6 & 71.11 & 28.89 & 65.00 & 35.00 \\
\hline 7 & 75.37 & 24.63 & 78.95 & 21.05 \\
\hline 8 & 82.84 & 17.16 & 72.50 & 27.50 \\
\hline
\end{tabular}

\section{Average Data for S ecurity Awareness based on Gen der}

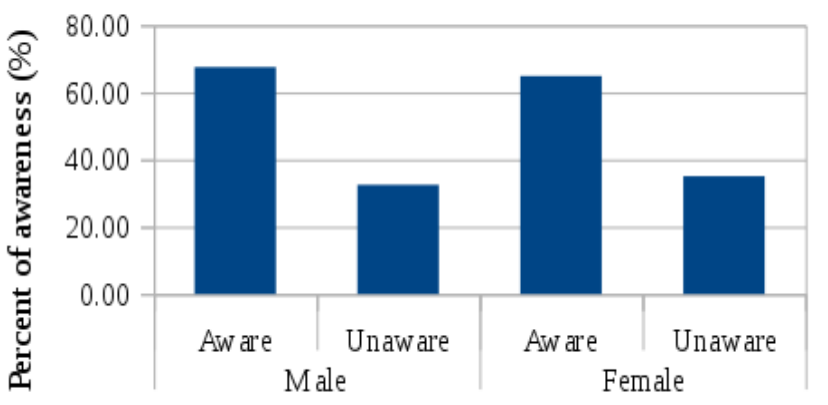

Awareness and Gender

Fig. 1: Average Data for Security Awareness on M-Money usage based on Respondents' Gender

On average, male respondents recorded $67.52 \%$ level of awareness on M-Money services usage which is slightly higher than that of females who scored $64.92 \%$. This implies that male respondents have higher level of awareness as compared to female respondents. It is however noted that the difference between male and female levels of awareness is small with only $2.6 \%$ between them. Fig. 1 summarizes the average of the security awareness of the respondents in security issues related to M-Money services based on gender 


\section{B. M-Money Security Awareness Based on the Level of Education}

For the level of security awareness based on the level of education, question number 1 underscored in this category as well. Respondents interviewed showed a low level of awareness with regard to changing the passwords periodically. With CSE and below group scoring $19.35 \%$, Pre University scoring $29.55 \%$ while degree and above group scoring $14.00 \%$. The highest level of awareness for degree and above respondents was observed on the question number 8 . Respondents in this category do not share their PIN with an agent to a level of $93.07 \%$. This is attributed to their level of understanding in using the M-Money services. CSE and Pre University showed a significant level of awareness on question number 3 with CSE and below scoring $89.66 \%$ and Pre University scoring $79.55 \%$ implying they are more careful when committing a transaction making sure no one can have access to their PINs.

TABLE III

M-MONEY SECURITY AWARENESS BASED ON LEVEL OF EDUCATION

\begin{tabular}{|l|c|c|c|c|c|c|}
\hline \multirow{2}{*}{ ID } & \multicolumn{2}{|c|}{ CSE and below } & \multicolumn{2}{c|}{ Pre Uni e rsity } & \multicolumn{2}{c|}{ Degree and above } \\
\cline { 2 - 7 } & Aware(\%) & $\begin{array}{c}\text { Un aware } \\
(\boldsymbol{\%})\end{array}$ & $\begin{array}{c}\text { Aware } \\
(\boldsymbol{\%})\end{array}$ & Unaware (\%) & Aware $(\%)$ & $\begin{array}{c}\text { Un aware } \\
(\%)\end{array}$ \\
\hline 1 & 19.35 & 80.65 & 29.55 & 70.45 & 14.00 & 86.00 \\
\hline 2 & 53.33 & 46.67 & 61.36 & 38.64 & 71.29 & 28.71 \\
\hline 3 & 89.66 & 10.34 & 79.55 & 20.45 & 79.21 & 20.79 \\
\hline 4 & 70.97 & 29.03 & 60.47 & 39.53 & 52.48 & 47.52 \\
\hline 5 & 87.10 & 12.90 & 77.27 & 22.73 & 89.00 & 11.00 \\
\hline 6 & 53.33 & 46.67 & 70.45 & 29.55 & 74.26 & 25.74 \\
\hline 7 & 88.89 & 11.11 & 72.73 & 27.27 & 74.26 & 25.74 \\
\hline 8 & 65.52 & 34.48 & 61.36 & 38.64 & 93.07 & 6.93 \\
\hline
\end{tabular}

The summary for security awareness of M-Money usage based on education level shows that on average respondents with a degree or above had the highest level of awareness as compared to other groups scoring $68.44 \%$ against that of Pre University which was $64.09 \%$ and $66.02 \%$ for CSE and below group. Fig. 2 illustrates the average awareness of respondents based on education level.

\section{Average D ata for Security Awarenes s based on Education level}

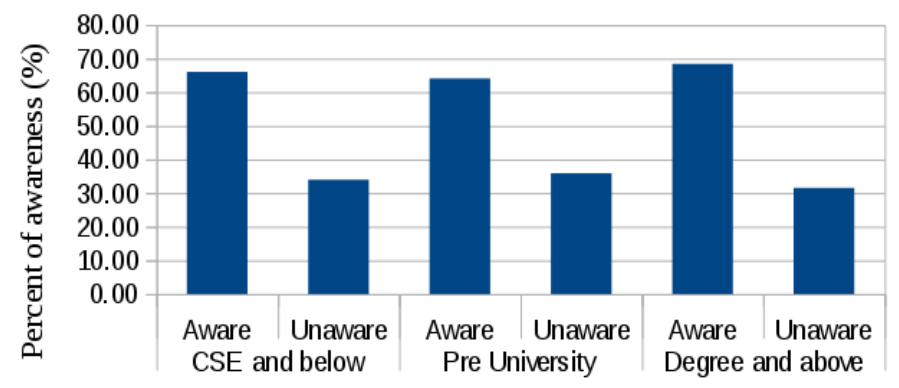

Awareness and level of education

Fig. 2: Average Data for Security Awareness on M-Money usage based on Education level

\section{M-Money Security Awareness Based on the Age of Respondents}

The age category experienced the same level of awareness on the question with the lowest level of awareness. All groups except the age group 18-25 years scored the lowest percentage of awareness on question 1 . With the age group below 18 years scoring 20\%, 25 - 36 years scoring $16.25 \%$ and the group 36 and above scoring 18.18\%. The age group 18-25 years showed the lowest level of understanding on question number 4 with $12.90 \%$ level of awareness. The highest level of awareness took a different shape in this category with varying results. The below 18 years group scored $90 \%$ on question number 7 . The age group $18-25$ years had $85.14 \%$ level of awareness on question number 5 , the group 26-35 years scoring $91.36 \%$ on question number 8 and the age group 36 years and above scoring $90.91 \%$ on question number 3 .

TABLE IV

M-MONEY SECURITY AWARENESS BASED ON AGE

\begin{tabular}{|c|c|c|c|c|c|c|c|c|}
\hline \multirow[t]{2}{*}{ ID } & \multicolumn{2}{|c|}{ Below 18 years } & \multicolumn{2}{|c|}{$18-25$ years } & \multicolumn{2}{|c|}{$26-35$ years } & \multicolumn{2}{|c|}{36 and above } \\
\hline & $\begin{array}{l}\text { Aware } \\
(\%)\end{array}$ & $\begin{array}{c}\text { Un Aware } \\
(\%)\end{array}$ & $\begin{array}{l}\text { Aware } \\
(\%)\end{array}$ & $\begin{array}{c}\text { Un Aware } \\
(\%)\end{array}$ & Aware $(\%)$ & $\begin{array}{l}\text { In Araare } \\
(\%)\end{array}$ & $\begin{array}{c}\text { A w a re } \\
(\%)\end{array}$ & $\begin{array}{c}\text { Un Aware } \\
(\%)\end{array}$ \\
\hline 1 & 20 & 80 & 21.62 & 78.38 & 16.25 & 83.75 & 18.18 & 81.82 \\
\hline 2 & 70 & 30 & 56.76 & 43.24 & 75 & 25 & 54.55 & 45.45 \\
\hline 3 & 66.67 & 33.33 & 83.78 & 16.22 & 78.75 & 21.25 & 90.91 & 9.09 \\
\hline 4 & 40 & $\begin{array}{ll}6 & 0\end{array}$ & 12.90 & 87.10 & 55.56 & 44.44 & 54.55 & 45.45 \\
\hline 5 & 80 & 0 & 85.14 & 14.86 & 87.5 & 12.5 & 81.82 & 18.18 \\
\hline 6 & 60 & 4 & 70.27 & 29.73 & 68.75 & 31.25 & 81.82 & 18.18 \\
\hline 7 & 90 & 0 & 74.65 & 25.35 & 77.78 & 22.22 & 60.00 & 40.00 \\
\hline 8 & 70 & 0 & 68.49 & 31.51 & 91.36 & 8.64 & 56.25 & 43.75 \\
\hline
\end{tabular}

In summary, the average security awareness based on age among the respondents ranks the age group 26-35 years as the most security aware group on the M-Money usage with $68.87 \%$ level of awareness. The other groups have $62.26 \%$ for 36 years and above, $62.08 \%$ for below 18 years and $59.20 \%$ arranged in descending order. Fig. 3 illustrates the different level of security awareness among the age groups. 
Average D ata for Security Awarenes s based on Age

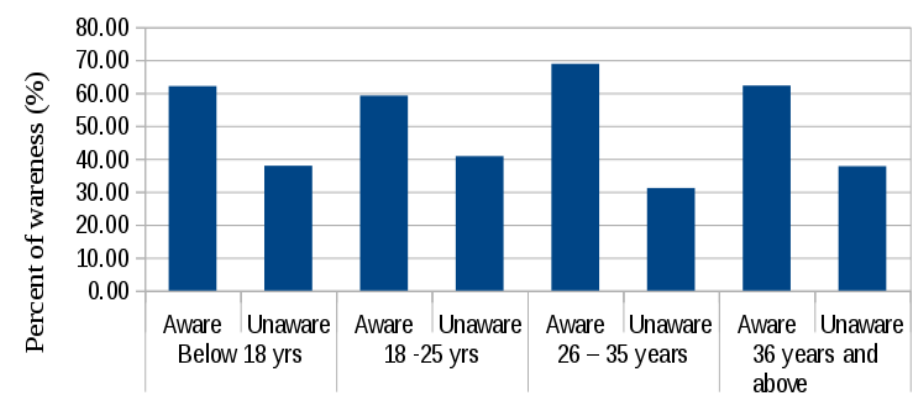

Age in years and awareness

Fig. 3: Average Data for Security Awareness on M-Money usage based on Age

\section{CONCLUSIONS}

The study aimed at studying the security awareness among different groups of M-Money users in Tanzania. The study reveals that generally, users have high security awareness when using the service. In terms of gender, male have higher security awareness than female respondents. It is also observed that in terms of age groups, the group with 26-35 years is more aware on the security matters than other groups. Results too reveal that respondents with a degree or above have the highest level of security awareness as compared to other respondents.

For M-Money users to continue using the service comfortably, they need to take care of serious concerns that may pose serious security bleaches. It is observed here that the customers falling within the age group 18-25 years and Pre University are lagging behind in terms of security awareness. Based on the findings, the promotion and campaigns towards safe use of the service should be targeted to the identified groups.

\section{REFERENCES}

[1] Ernst \& Young (2009). Mobile money: An overview for Global Telecommunications operators.

[2] C. Pénicaud, A. Katakam, "Mobile Money for the Unbanked State of the Industry 2013 Mobile Financial Services for the Unbanked", GSMA, 2013.

[3] The Bank of Tanzania (June, 2014), Monetary Policy Statement 2014/2015. ISSN 0856-6976J.

[4] A. B. Mtaho, L. Mselle, "Securing Mobile Money Services in Tanzania: A Case of Vodacom M-Pesa", International journal of Computer Science \& Network Solutions, 2014-Volume 2. No5 ISSN 2345-3397.

[5] A. Ally, "The prospects and legal challenges posed by M-Payments and M-banking services in Tanzania", Open University Law Journal, 2014, Vol. 5, No. 1:49-57.

[6] B. Masamila, "State of mobile banking in Tanzania and Security issues", International Journal of Network Security \& Its Applications (IJNSA), Vol.6, No.4, July 2014.

[7] A. Harris, S. Goodman, P. Traynor, "Privacy and Security Concerns Associated with Mobile Money Applications in Africa", Washington Journal Of Law, Technology \& Arts Volume 8, Issue 3 Mobile Money Symposium 2013.
[8] Vodacom Tanzania (2013). M-Pesa Terms and conditions. Last accessed 06 December 2014. Source: www.vodacom.co.tz/.../MESA_Terms_and_Condititions.

[9] Inter Media (2013). Mobile Money in Tanzania, Use, Barriers and Opportunities: The Financial Inclusion Tracker Surveys Project.

[10] F. Sidi, M. A. Jabar, A. Mustapha, N. F.Sani,I. Ishak, S.R. Supian "Measuring Computer Security Awareness On Internet Banking And Shopping For Internet Users", Journal of Theoretical and Applied Information Technology, Vol. 53 No.2, 2013. 